\title{
Assessing the intention to use technology among pre-service teachers in Singapore and Malaysia: A multigroup invariance analysis of the Technology Acceptance Model
}

(TAM)

\begin{abstract}
This study assesses the pre-service teachers' self-reported future intentions to use technology in Singapore and Malaysia. A survey was employed to validate items from past research. Using the Technology Acceptance Model (TAM) as a research framework, 495 pre-service teachers from Singapore and Malaysia responded to an 11-item questionnaires containing four constructs: intention to use (ITU), attitude towards computer use (ATCU), perceived usefulness (PU), and perceived ease of use (PEU). Structural equation modelling (SEM) was employed as the main method of analysis in this study. A multi-group analysis of invariance was performed on the two samples. The results show that configural and metric invariance were fully supported while scalar and factor variance invariance were partially supported, suggesting that the 11-item measure of the TAM may be robust across cultures and that the factor loading pattern and factor loadings appeared to be equivalent across the cultures examined. While all the paths in the structural model were significant, the variance accounted for in the dependent variable (ITU) was much larger in the Malaysian sample relative to the Singaporean sample.
\end{abstract}

Keyword: technology, pre-service, teacher, Malaysia, Singapore 